\title{
Estimation of Seismic Hazard Potential and Attendant Potential Human Fatalities from a Scenario Earthquake on the Sanchiao Fault in Northern Taiwan
}

\author{
Kun-Sung Liu \\ Department of Civil Engineering \& Hazard Mitigation Research Center, Kao Yuan University, Kaohsiung, Taiwan, ROC
}

Email address:

lk.sung99@msa.hinet.net, tf0143@cc.kyu.edu.tw

\section{To cite this article:}

Kun-Sung Liu. Estimation of Seismic Hazard Potential and Attendant Potential Human Fatalities from a Scenario Earthquake on the Sanchiao Fault in Northern Taiwan. Earth Sciences. Vol. 9, No. 1, 2020, pp. 16-31. doi: 10.11648/j.earth.20200901.13

Received: December 19, 2019; Accepted: January 2, 2020; Published: January 9, 2020

\begin{abstract}
In this article, the seismic hazard potential in northern Taiwan, including Taipei City, New Taipei City, Keelung City and northern Taoyuan areas are estimated in the form of peak ground acceleration, peak ground velocity and Modified Mercalli Intensity as well as to assess attendant potential human fatalities from a scenario earthquake on the Sanchiao active fault in these areas. By using ground motion prediction equation method in a case of Mw6.88 resulting in the ShakeMap patterns of ground motion, showed the areas of PGA above 400 gals are located in the regions inside the yellow lines of the PGA contour map. Furthermore, the areas of PGA greater than 637 gal are located in the northern Bali and the border area of Sinjhuang and Shulin. Likewise, the high PGV area greater than $60 \mathrm{~cm} / \mathrm{s}$ are located in the border area of Sinjhuang, Taishan and Shulin. In addition, from estimation of potential human fatalities for a scenario earthquake on the Sanchiao active fault, it is noted that potential fatalities increase rapidly in people above age 45. Total fatalities reach a high peak in age groups of 5564. Another to pay special attention by Taipei City Government is the number and percentage of fatalities above age 85 are more in Taipei City with values of 419 and $8.54 \%$ than New than Taipei City with values of 319 and $5.02 \%$. In addition, it is surprising that the number and percentage of fatalities are 1234 and $9.75 \%$, respectively in Taoyuan City. Overall, the results of this paper will enable both local and central governments in Taiwan to take notice of potential earthquake threat in these areas, as well as to improve decision making with respect to emergency preparedness, response, and recovery activities for earthquakes in northern Taiwan.
\end{abstract}

Keywords: Sanchiao Fault, Seismic Hazard Potential, Potential Human Fatality, ShakeMap, Northern Taiwan

\section{Introduction}

Taiwan is located on the boundary of the Eurasian continental plate and the Philippine Sea plate, so seismic activity is very frequent. Historically, there were several damaging earthquakes had occurred in northern Taiwan during the last four hundred years. Some of these earthquakes had resulted in heavy loss of human lives, such as 1694 Taipei earthquake, 1867 Keeling earthquake, 1986 Hualien earthquake and 1999 Chi-Chi earthquake. After 2010, the Central Geological Survey (CGS) upgraded the Sanchiao active fault from suspected fault to Category II, the assessment of potential seismic hazards has been more attentive in northern Taiwan, including Taipei City, New Taipei City, Keelung City and northern Taoyuan areas [1]. Accordingly, a high seismic disaster potential due to a damaged earthquake most likely occur on the Sanchiao active fault. Hence, the central and local government needs to put in more efforts on earthquake disaster prevention in these areas to reduce probably earthquake losses.

To effectively assess the potential risk of earthquakes and possible disasters and losses, and apply them to the risk assessment and management of government disaster prevention, the National Center for Research on Earthquake Engineering (NCREE) of Taiwan developed an Earthquake Loss Estimation System (TELES) to promote research on seismic hazard analysis [2]. In addition, some studies estimated potential seismic hazards and assessed potential human fatalities from scenario earthquakes on the corresponding active faults in these areas. Particularly, the 
site response factor is considerable in their ground motion prediction models in order to obtain more realistic seismic ground motion estimates for assessment of potential seismic hazards [3-7].

Seismic intensity has traditionally been used worldwide as a method for quantifying the shaking pattern and the extent of damage for earthquake [8]. In Taiwan, the intensity scale used by the Central Weather Bureau (CWB) is conducted and depended on the peak ground acceleration. In contrast, the ShakeMap developed by the United States Geological Survey (USGS) provides a means of generating not only peak ground acceleration and velocity maps, but also a Modified Mercalli Intensity (MMI) map [8]. Liu et al., [4] estimated the seismic hazard potential in Taiwan based on ShakeMaps, showed the areas of MMI intensity greater than VIII are located in the Chianan plains. In addition, Liu and Tsai [9] estimated the potential death tolls due to large future earthquakes in Chianan area by using a formula established by Tsai et al, [10] that relate the human fatality rate with age, together with the age distribution of the population that could be affected by scenario earthquakes on the Meishan, Chukou and Hsinhua active faults.

Overall, I first find out the high seismic hazard areas in northern Taiwan in term of PGA, PGV and MMI. Furthermore, I will assess potential death tolls due to a large future earthquake occurring on the Sanchiao active fault. The results of this study will show areas with higher earthquake disaster potential in northern Taiwan. They can serve as critical information for emergency response planning. They will also provide valuable information for site evaluation of critical facilities in high earthquake hazard regions.

\section{The Study Area and Data Used}

The area of this study, northern Taiwan covers these jurisdictions of Taipei City, New Taipei City, Keelung City and the northern Taoyuan City (Figure 1). The Taipei city and the suburbs of a typical basin, the surrounding terrain with southeast of many hills, northeast more mountains, the northwest is flat, the west of the Danshuei river. Overall, the terrain dipped from north to south, altitude between 20 meters to 1,100 meters. The exposed formations in Taipei City are dominated by sedimentary rock, and the Datun volcano complex in the northwest is the eruption of the andesite flow and Tuff breccia. The alluvial layer is distributed in the Taipei Basin, the river channel and the coastal area. The Taipei metropolitan area is centered on the flat-terrain Taipei Basin, which gradually spreads to hilly areas, volcanic clusters and terraces around, and is filled with Late Pleistocene and Holocene alluvial layers. The flat ground formed by these unsolid sediments is the focus for the development of the Taipei metropolitan area [11].

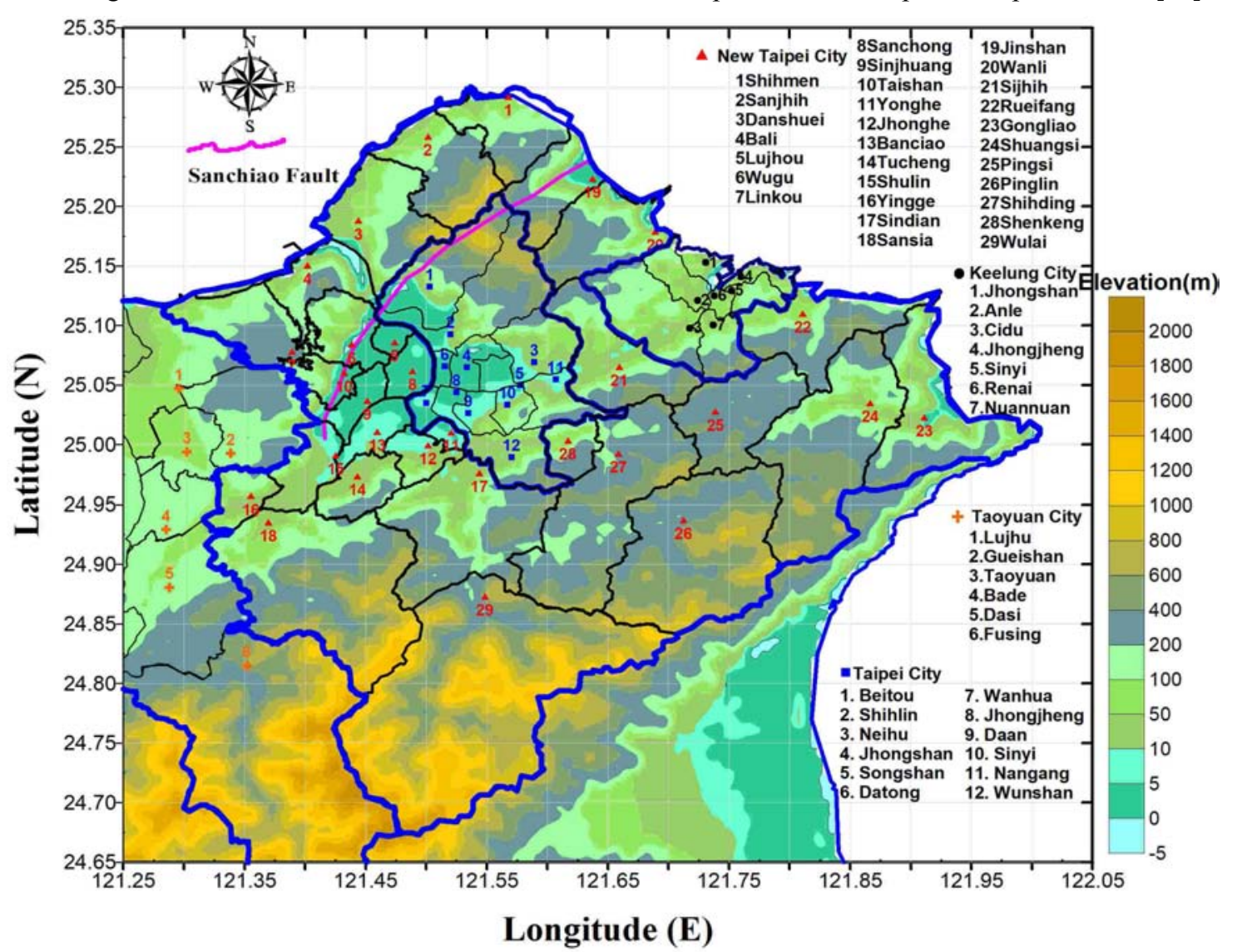

Figure 1. Topographic map of the northern Taiwan, showing the Sanchiao active fault (mapped by the Taiwan CGS) and these administrative districts in Taipei City, New Taipei City, Keelung City and northern Taoyuan City. 
New Taipei City is located around Taipei City and Keelung City, forming a large Taipei metropolitan area, living together, and with Taoyuan City, Ilan county border. New Taipei City is $68.4 \mathrm{~km}$ long in the east-west direction, with a length of 69.1 $\mathrm{km}$ in the north-south direction. The city is also facing the sea on the north and east sides, along the boundary with Ilan County in southern and Taoyuan City in western. The total length of the coastline is more than $120 \mathrm{~km}$. The terrain of the New Taipei City is composed of four main terrains, such as Taipei Basin, Datun Volcano Group, Linkou Tableland and alpine hills. The northern part is the volcanic terrain of Datun Mountain, the eastern and southern mountains are the mountainous and hilly terrain of the Snowy Mountains, and the Linkou in the southwest is the terrain of Tableland. The area of the Banciao, Sanchong and Sinjhuang Districts, located in the western part of the Taipei Basin, belongs to the alluvial distribution. [12].

The distribution of average population density in northern Taiwan is shown in Figure 2 and given in Table 1 [13]. There are 12 jurisdiction districts with a total population of 2,686,516 in Taipei City [13]. The population density is 9,940 people per square kilometer [11]. The numbers and names of 12 jurisdiction districts are as follows: 1 Beitou, 2 Shihlin, 3 Neihu, 4 Jhongshan, 5 Songshan, 6 Datong, 7 Wanhua, 8 Jhongjheng, 9 Daan, 10 Sinyi, 11 Nangang and 12 Wunshan. In addition, New Taipei City has 29 jurisdiction districts with a total population of
$3,954,929$ [13]. The numbers and names of 29 jurisdiction districts are as follows: 1 Shihmen, 2 Sanjhih, 3 Danshuei, 4 Bali, 5 Lujhou, 6 Wugu, 7 Linkou, 8 Sanchong, 9 Sinjhuang, 10 Taishan, 11 Yonghe, 12 Jhonghe, 13 Banciao, 14 Tucheng, 15 Shulin, 16 Yingge, 17 Sindian, 18 Sansia, 19 Jinshan, 20 Wanli, 21 Sijhih, 22 Rueifang, 23 Gongliao, 24 Shuangsi, 25 Pingsi, 26 Pinglin, 27 Shihding, 28 Shenkeng and 29 Wulai. Keelung City has 7 jurisdiction districts with a total population of 373,649 [13]. The numbers and names of 7 jurisdiction districts are as follows: 1 Jhongshan, 2 Anle, 3 Cidu, 4 Jhongjheng, 5 Sinyi, 6 Ren-ai and 7 Nuannuan.

Furthermore, Taoyuan City has 13 jurisdiction districts with a total population of 2,054,260 [13]. The numbers and names of 13 jurisdiction districts are as follows: 1 Lujhu, 2 Gueishan, 3 Taoyuan, 4 Bade, 5 Dasi, 6 Fusing, 7 Dayuan, 8 Jhongli, 9 Pingjhen, 10 Longtan, 11 Guanyin, 12 Sinwu, and 13 Yangmei. Topographic map of the northern Taiwan and these administrative districts as well as the Sanchiao active fault (mapped by the Taiwan CGS) [1] (CGS, 2014) are also shown in Figure 1. The administrative districts of high population density between 20,000 and 41,000 per $\mathrm{km}^{2}$ can be seen in Songshan, Datong, Wanhua, Jhongjheng, Daan, Sinyi, Lujhou, Sanchong, Sinjhuang, Yonghe, Jhonghe, and Banciao districts, all located in Taipei basin. Areas of high population density between 10,000 and 20,000 per $\mathrm{km}^{2}$ can be seen in Jhongshan, Renai and Taoyuan districts.

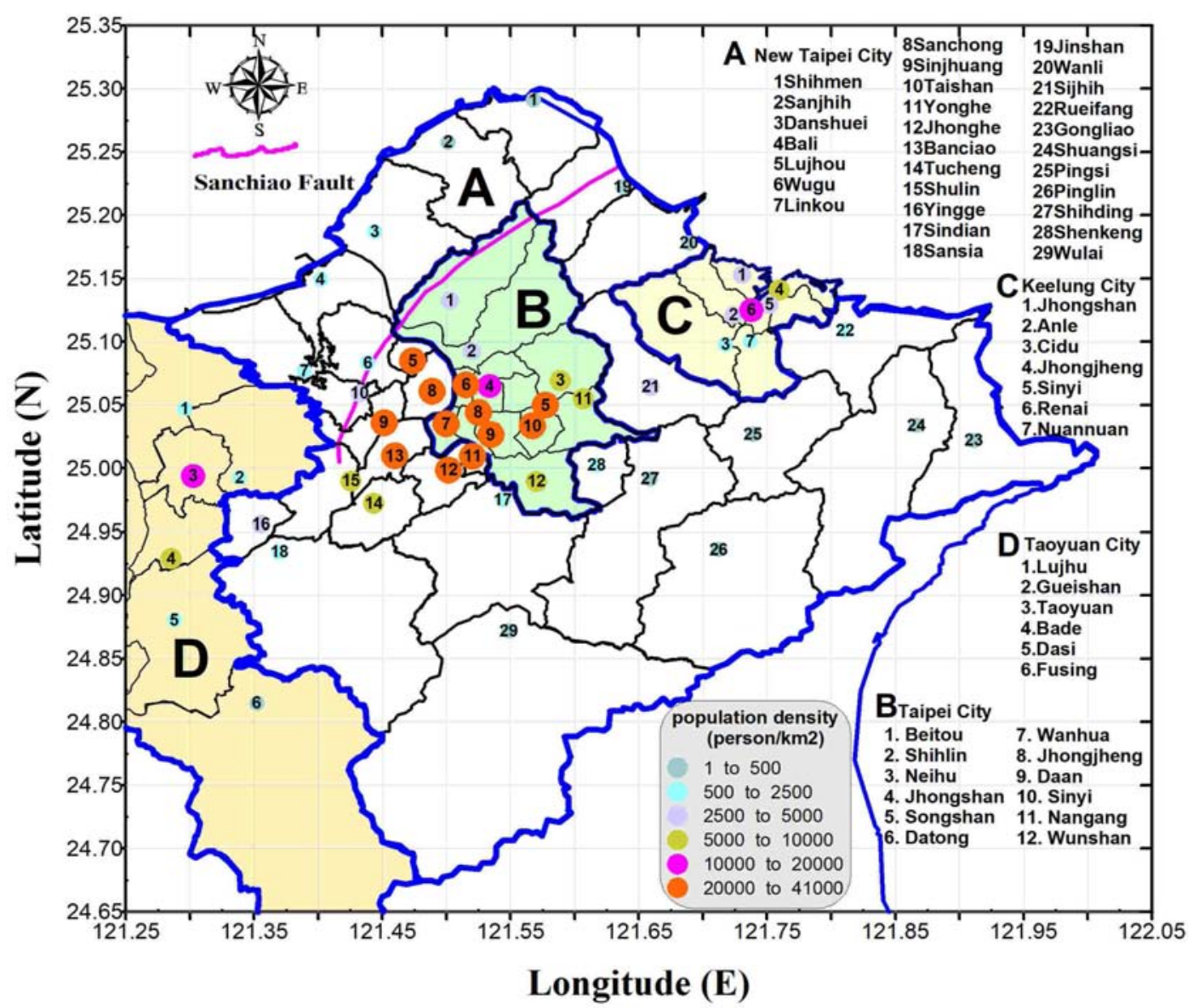

Figure 2. Population density map of the northern Taiwan. The Sanchiao active fault and the corresponding administrative districts are also shown. 
Table 1. Population and Population density of the administrative districts of northern Taiwan*

\begin{tabular}{|c|c|c|c|c|c|c|c|c|c|c|c|}
\hline \multicolumn{4}{|c|}{ Taipei City $(2,686,516)$} & \multicolumn{4}{|c|}{ New Taipei City $(3,954,929)$} & \multicolumn{4}{|c|}{ Keelung City $(374,914)$} \\
\hline No & Region & Pop. & Pop.D. & No & Region & Pop. & Pop.D. & No & Region & Pop. & Pop.D \\
\hline 1 & Beitou & 255444 & 4496 & 1 & Shihmen & 12794 & 250 & 1 & Jhongshan & 49254 & 4680 \\
\hline 2 & Shihlin & 289742 & 4646 & 2 & Sanjhih & 23464 & 356 & 2 & Anle & 81906 & 4544 \\
\hline 3 & Neihu & 282842 & 8957 & 3 & Danshuei & 155241 & 2197 & 3 & Cidu & 54041 & 960 \\
\hline 4 & Jhongshan & 228753 & 16719 & 4 & Bali & 36201 & 917 & 4 & Jhongjheng & 53571 & 5246 \\
\hline 5 & Songshan & 210343 & 22647 & 5 & Lujhou & 199426 & 26822 & 5 & Sinyi & 51248 & 4803 \\
\hline 6 & Datong & 129820 & 22850 & 6 & Wugu & 81744 & 2345 & 6 & Ren-ai & 47034 & 11110 \\
\hline 8 & Jhongjheng & 163140 & 21446 & 8 & Sanchong & 389813 & 23890 & & & & \\
\hline 9 & Daan & 313363 & 27581 & 9 & Sinjhuang & 409760 & 20760 & & & & \\
\hline 10 & Sinyi & 228496 & 20387 & 10 & Taishan & 77939 & 4068 & \multicolumn{4}{|c|}{ Taoyuan City $(2,044,023)$} \\
\hline 11 & Nangang & 119752 & 5483 & 11 & Yonghe & 229062 & 40089 & No & Region & Pop. & Pop.D \\
\hline \multirow[t]{17}{*}{12} & Wunshan & 271341 & 8612 & 12 & Jhonghe & 415742 & 20639 & 1 & Lujhu & 149852 & 1985 \\
\hline & & & & 13 & Banciao & 556920 & 24070 & 2 & Gueishan & 140509 & 1951 \\
\hline & & & & 14 & Tucheng & 239258 & 8095 & 3 & Taoyuan & 415414 & 11936 \\
\hline & & & & 15 & Shulin & 183407 & 5536 & 4 & Bade & 179502 & 5325 \\
\hline & & & & 17 & Sindian & 299017 & 2487 & 6 & Fusing & 10625 & 30 \\
\hline & & & & 18 & Sansia & 110010 & 575 & 7 & Dayuan & 83586 & 956 \\
\hline & & & & 19 & Jinshan & 22392 & 455 & 8 & Jhongli & 378918 & 4952 \\
\hline & & & & 20 & Wanli & 22618 & 357 & 9 & Pingjhen & 211146 & 4422 \\
\hline & & & & 21 & Sijhih & 194200 & 2726 & 10 & Longtan & 115728 & 1538 \\
\hline & & & & 22 & Rueifang & 41490 & 587 & 11 & Guanyin & 63003 & 716 \\
\hline & & & & 23 & Gongliao & 13306 & 133 & 12 & Sinwu & 48025 & 565 \\
\hline & & & & 24 & Shuangsi & 9412 & 64 & 13 & Yangmei & 155754 & 1748 \\
\hline & & & & 25 & Pingsi & 5002 & 70 & & & & \\
\hline & & & & 26 & Pinglin & 6460 & 38 & & & & \\
\hline & & & & 27 & Shihding & 7848 & 54 & & & & \\
\hline & & & & 28 & Shenkeng & 23622 & 1148 & & & & \\
\hline & & & & 29 & Wulai & 6036 & 19 & & & & \\
\hline
\end{tabular}

* Note:

(1) Data source: National Statistics (2014).

(2) Pop. = Population.

(3) Pop.D. = Population Density.

The major active structure of the Taipei Domain is the Shanchiao fault distributes in the northwestern of Taipei area, which separates the Taipei Basin and the Linkou Tableland. The Sanchiao active fault belongs to Type II, namely late Pleistocene active fault [1]. The observation of numerous triangular facets along the eastern foothills of the Linkou Tableland led to the discovery of the fault many decades ago [14]. NW-SE extension across the Taipei Domain is concentrated on one principal normal fault, across which the long-term rate of extension appears to be at least $1 \mathrm{~mm} / \mathrm{yr}$. Motion across this structure, the Shanchiao fault, has been producing the Taipei Basin half graben for the past few hundred thousand years. Seismic slip on the fault may have produced a marine incursion into the Taipei Basin in 1694. History records a very interesting occurrence that is quite relevant to understand the relevance of the Shanchiao fault to seismic hazard assessment. In 1694, historical documents indicate an abrupt subsidence in the Taipei region, with the formation of a brackish water lake that inundated at least a third of the basin $[14,15]$, Apparently, Taipei area has high seismic hazard potential. Not only population increase, but also the slow rebuilding of old buildings, a giant earthquake is likely to cause severe damages. Hence, effective earthquake disaster prevention measures in the metropolitan areas will be required in order to reduce future earthquake loss [16-19].
The Sanchiao fault is a normal fault with a length of $34 \mathrm{~km}$, divided into two segments: The northern section ranged southward from Jinshan District of New Taipei City to Beitou District of Taipei City with a length of $21 \mathrm{~km}$. The southern section ranged southward from the Beitou District of Taipei City to Shulin District of New Taipei City with a length of 13 $\mathrm{km}$. [1]. The estimated magnitude value for Sanchiao fault according the empirical relationships between the magnitude and rupture length of fault developed by Wells and Coppersmith [20], would be Mw6.88 corresponding to a fault length of $34 \mathrm{~km}$. Furthermore, based on the information from TELES developed by the NCREE [2] and CGS [1], the focal depth of the scenario earthquakes on Sanchiao fault was assumed to be $10 \mathrm{~km}$. Accordingly, Mw6.88 will use to estimate the PGA, PGV and MMI and attendant potential human fatalities in northern Taiwan.

In addition, the site response factor at each grid is as the site effect parameter included in the ground motion prediction model. These predictive relationships are obtained by using the Taiwan Strong Motion Instrumentation Program (TSMIP) network data operated by the CWB of Taiwan to estimate peak ground motion at all grid points [6, 21, and 22]. These numerous high-quality instrumental recordings of TSMIP provide an excellent database for making various earthquake engineering and seismological studies. [4, 5, 23]. 


\section{Methodology}

\subsection{Maximum Ground Motion Parameters}

Attenuation relationships, or "Ground Motion Prediction Equations (GMPEs)", provide an efficient means for predicting the level of ground shaking at any given location, and for use in seismic hazard analyses. An attenuation relationship is a mathematical equation that relates PGA and PGV to a number of seismological parameters, such as the earthquake source, the wave propagation path between the source and the site, and the site condition. In this study, to obtain ShakeMap, I use the attenuation relationship provided by Liu and Tsai $[6,22]$ to calculate the PGA and PGV. Furthermore, an MMI map also has uses in combination by PGA and PGV. It makes easier to relate the recorded ground motions to the shaking intensity and attendant damage by using the MMI map [8].

The maximum ground motion parameters inside a block provide a means to assess the potential earthquake hazard in a region. [9] At first, I use these predictive relationship of Liu and Tsai [6] to estimate PGA and PGV for each grid point with a block size of $0.01^{\circ} \times 0.01^{\circ}$ (or roughly $1 \mathrm{~km} \times 1 \mathrm{~km}$ ). In this step, the Sanchiao active fault with a length of $34 \mathrm{~km}$ was used as a line source to calculate the seismic ground motion. Next, to correct the amplitude at that location using a site response factor determined by Liu and Tsai [6, 22], as shown in Figures 3 and 4. Examination of the residuals, site response factor, for sites with qualitative soil categories is a useful method for sets of records. The site response factor $r$, is defined as the difference between the logarithms of the observed and the predicted ground motion. The site amplification values can be calculated from $\exp (r)$ [6]. Finally, I combine above results with the estimated PGA and PGV into MMI maps.

In this study, three levels of ground shaking from the Taiwan intensity scale used by the Central Weather Bureau of Taiwan (CWBI) and MMI intensity scales are considered to be of interest: CWBI V represents a threshold for "minor damage", and CWBI VI and CWBI VII the thresholds for "moderate damage" and "severe damage", respectively. For the MMI intensity scale, MMI VI, MMI VII and MMI VIII represent the thresholds for "light", "moderate" and "heavy" damage, respectively. The CWBI and MMI scale are given in Tables 2 (URL http://www.cwb.gov.tw/ in/seismic/quake preparedness.htm) and $\quad 3$ (URL http://earthquake.usgs.gov/eqcenter/shakemap/background.p $\mathrm{hp}$ ), respectively.

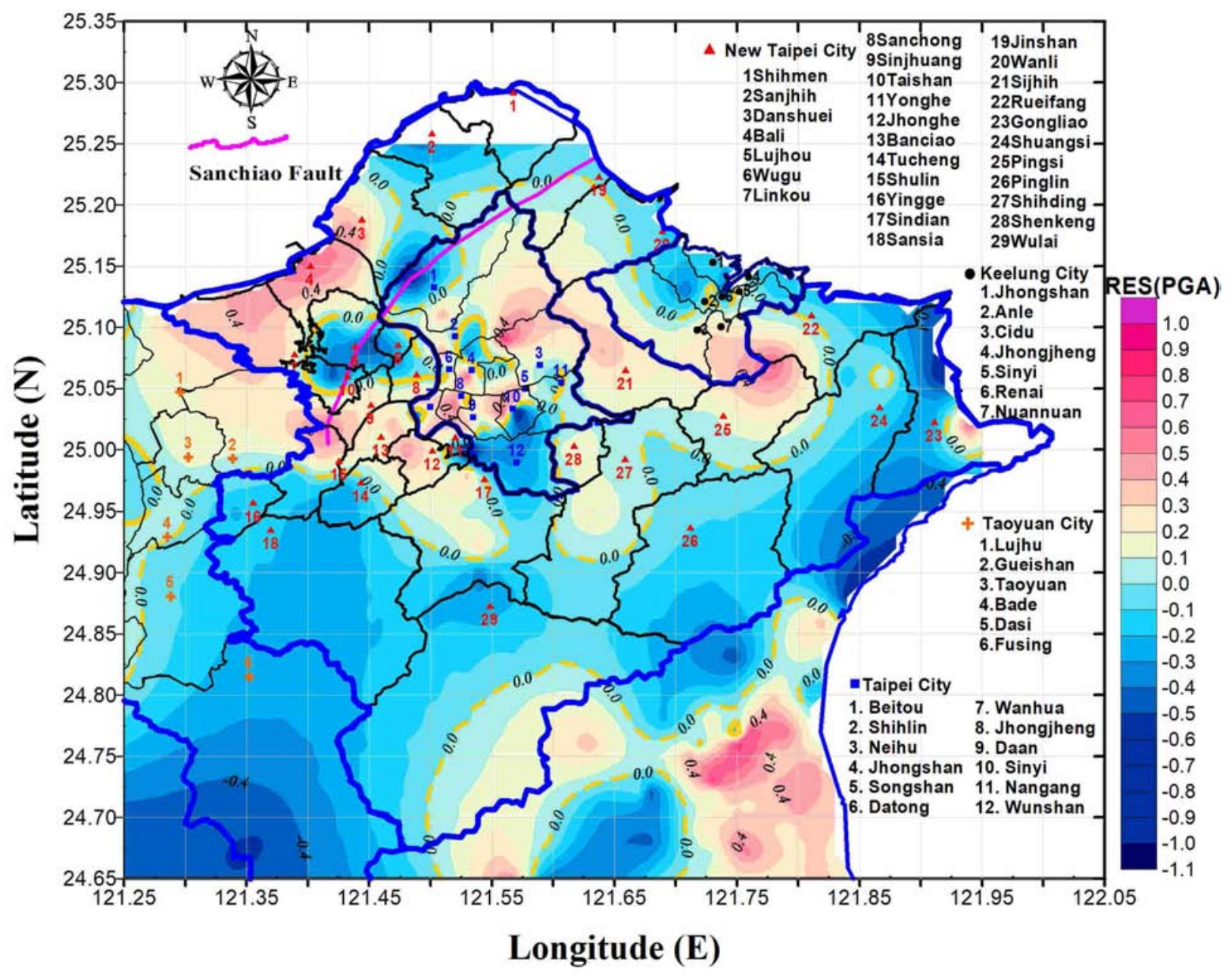

Figure 3. Distribution of the site response factor for PGA in the northern Taiwan. The site response factor is defined as the residual value r that is the difference between logarithms of the observed and the predicted PGA, The amplification values of site response can be calculated from exp (r). 


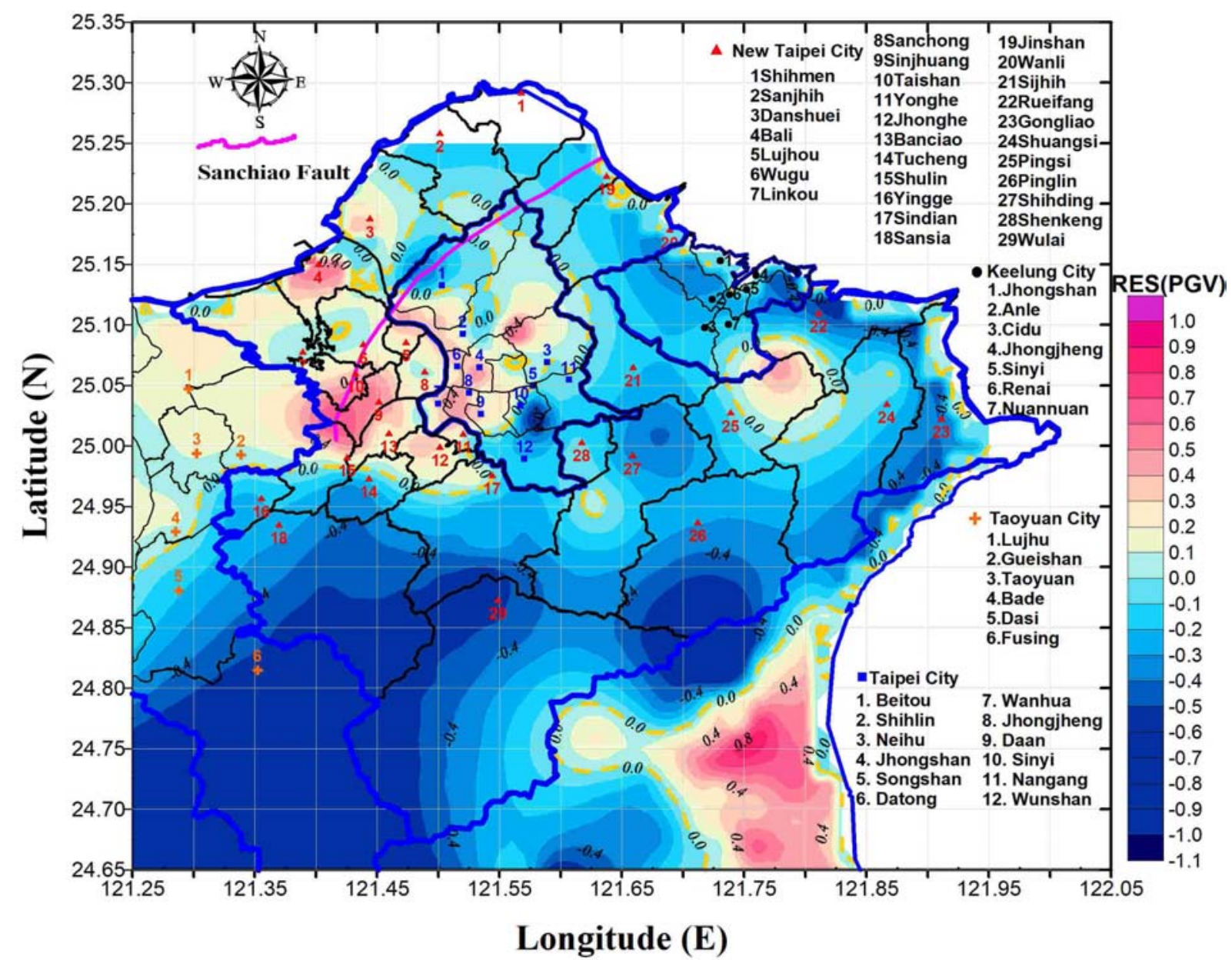

Figure 4. Distribution of the site response factor for PGV in the northern Taiwan. The site response factor is defined as the residual value $r$ that is the difference between logarithms of the observed and the predicted PGV, The amplification values of site response can be calculated from exp (r).

Table 2. Central Weather Bureau Intensity Scale (CWBI) of Taiwan.

\begin{tabular}{|c|c|c|c|c|c|c|c|c|}
\hline \multirow{2}{*}{ Intensity Scale } & 0 & 1 & 2 & 3 & 4 & 5 & 6 & 7 \\
\hline & Micro & Very minor & Minor & Light & Moderate & Strong & Very Strong & Great \\
\hline Peak Acc. $\left(\mathrm{cm} / \mathrm{s}^{2}\right)$ & $<0.8$ & $0.8 \sim 2.5$ & $2.5 \sim 8.0$ & $8 \sim 25$ & $25 \sim 80$ & $80 \sim 250$ & $250 \sim 400$ & $>400$ \\
\hline $\begin{array}{l}\text { Effects } \\
\text { Or Damage }\end{array}$ & & & $\begin{array}{l}\text { Hanging lamps } \\
\text { vibrate slightly. }\end{array}$ & $\begin{array}{l}\text { Buildings shake, } \\
\text { hanging objects } \\
\text { shake visibly. }\end{array}$ & $\begin{array}{l}\text { Buildings rock } \\
\text { noticeably; may } \\
\text { cause slight damage. }\end{array}$ & $\begin{array}{l}\text { Walls crack; some } \\
\text { chimneys and } \\
\text { large archways } \\
\text { topple over. }\end{array}$ & $\begin{array}{l}\text { Damage to some } \\
\text { buildings, doors } \\
\text { and windows } \\
\text { bend. }\end{array}$ & $\begin{array}{l}\text { Severe damage to } \\
\text { or collapse of some } \\
\text { buildings; } \\
\text { underground lines } \\
\text { break. }\end{array}$ \\
\hline
\end{tabular}

Table 3. Modified Mercalli Intensity Scale (MMI).

\begin{tabular}{|c|c|c|c|c|c|c|c|c|c|c|}
\hline Estimated & tensity & $\mathbf{I}$ & II-III & IV & $\mathbf{V}$ & VI & VII & VIII & IX & $\mathbf{X}+$ \\
\hline \multirow{2}{*}{ Peak Acc. } & $\% \mathrm{~g}$ & $<0.17$ & $0.17-1.4$ & $1.4-3.9$ & $3.9-9.2$ & $9.2-18$ & $18-34$ & $34-65$ & $65-124$ & $>124$ \\
\hline & gal & $<1.7$ & $1.7-13.7$ & $13.7-38.2$ & $38.2-90.2$ & $90.2-176$ & $176-333$ & $333-637$ & $637-1215$ & $>1215$ \\
\hline \multicolumn{2}{|c|}{ Peak Vel. $(\mathrm{cm} / \mathrm{s})$} & $<0.1$ & $0.1-1.1$ & $1.1-3.4$ & $3.4-8.1$ & $8.1-16$ & $16-31$ & $31-60$ & $60-116$ & $>116$ \\
\hline \multicolumn{2}{|c|}{ Perceived Shaking } & Not Felt & Weak & Light & Moderate & Strong & Very Strong & Severe & Violent & Extreme \\
\hline \multicolumn{2}{|c|}{ Potential Damage } & None & None & None & Very Light & Light & Moderate & Moderate/Heavy & Heavy & Very Heavy \\
\hline
\end{tabular}

\subsection{Assessment of Human Fatality}

Human safety is a primary goal of most modern earthquake protection programs. It is necessary to be an effective earthquake protection program to include reliable estimation of life loss in future earthquakes. However, document including the data of fatalities in past earthquakes are relatively rare [10, 24]. Tsai et al., [10] made a correlation between age and the human fatality rate caused by the 1999 Chi-Chi earthquake in Taiwan. Their results showed a clear age dependence of the fatality rate was observed independently based on demographic data from the two 
hardest-hit Nantou and Taichung counties by the Chi-Chi earthquake. The empirical data sets for both counties show nearly identical behavior and can be represented by almost the same regression formula. Overall, the estimation of total human fatalities in individual townships located inside the seismic intensity greater than 250 gals can be made by using the following equation $[7,9,10,19,25]$ :

$$
Y \%=0.00022 X^{2}-0.01 X+0.16
$$

Where $Y \%$ is the age-group fatality rate in percentage, and $X$ represents age.

The age dependence of human fatality rate used in above equation to calculate the number of fatalities is conducted from the Chi-Chi earthquake. The fatality rate model in this study should be more suitable for night time because the Chi-Chi earthquake occurred at midnight, almost all residents were at home. The building collapse became the most dominant cause of fatalities [10]. The situation was consistent with the study result of Pai et al., that the primary cause of death of the victims of the Chi-Chi earthquake was structural failure and the building types [26]. On the other hand, the corresponding fatality rate should be reduced due to a better building quality is expected for building code revisions after 1999.

\section{Results and Discussion}

\subsection{Maximum Ground Motion Parameters}

At first, to contour the ShakeMaps, I use a magnitude value of Mw6.88 to estimate the maximum ground motions at each grid point of the study area. Figure 5 shows the PGA ShakeMap for an Mw6.88 scenario earthquake on the Sanchiao active fault in northern Taiwan. Locations of the 12 administrative districts of Taipei City, 29 administrative districts of the New Taipei City, 7 administrative districts of Keelung City and 7 administrative districts of northern Taoyuan as well as Sanchiao active fault are also shown. The results reveal that high PGA areas greater than 400 gals, corresponding to CWB intensity greater than VII (referred to Table 2), as shown in the regions inside the yellow lines in Figure 5 are located in the following regions: Eastern and southern Beitou, Shihlin, northern Neihu, Jhongshan, Songshan, Datong, Wanhua, Jhongjheng, western Daan and northwestern Sinyi in the Taipei City. Similarly, high PGA areas greater than 400 gals are also located in southern Shihmen, southern Sanjhih, western Danshuei, Bali, northeastern Lujhou, northern Wugu, Linkou, eastern and southern Sanchong, Sinjhuang, southern Taishan, northern Yonghe, Jhonghe, Banciao, northeastern Tucheng, northern Shulin, Jinshan, western Wanli and northwestern Sijhih in the New Taipei City as well as eastern Lujhu, Gueishan and northeastern Taoyuan in the Taoyuan City. Furthermore, the areas of PGA above 500 gals are as shown in the regions filled with purple in Figure 5. The high PGA areas greater than 637 gal, corresponding to MMI intensity greater than IX (referred to Table 3), are located in the northern Bali and the border area of Sinjhuang and Shulin. Similarly, the PGV ShakeMap is shown in Figure 6. It can be seen that the areal patterns of high PGV greater than 31 $\mathrm{cm} / \mathrm{s}$, corresponding to MMI intensity greater than VIII (referred to Table 3), are similar to that of the PGA. Furthermore, the high $\mathrm{PGV}$ areas greater than $60 \mathrm{~cm} / \mathrm{s}$, corresponding to MMI intensity greater than IX, are located in the border area of Sinjhuang, Taishan and Shulin.

In addition to CWB intensity of Taiwan, the MMI is widely used all over the world to represent the level of ground shaking following a damaging earthquake [8]. Hence, I obtain an MMI intensity map, based on a combination of estimated maximum value for PGA and PGV, as shown in Figure 7. It can be seen that the patterns of high MMI greater than VIII, are similar to the contour pattern of the PGV greater than $31 \mathrm{~cm} / \mathrm{s}$ as shown in Figure 6. In summary, the ShapeMaps for PGA, PGV and MMI, respectively shown in Figures 5-7 can provide critical information to assess potential earthquake hazards in northern Taiwan.

From Figures 2 to 7 mentioned above, I can find the following features: (1) The areas with PGA greater than 400 gals, corresponding to CWB intensity VII and PGV greater than $31 \mathrm{~cm} / \mathrm{s}$, corresponding to MMI intensity greater than VIII is due to the combined effects of the large site response factors and Sanchiao fault. For instance, in the border area of Sinjhuang and Shulin can be found the high site amplification factors of 1.65 and 1.82 for PGA and $\mathrm{PGV}$, respectively, as shown in Figures 3 and 4. (2) In addition, not always the highest PGA values distributed in the fault rupture areas due to the effect of low site response factors as shown in Figure 5. For instance, in northwestern Beitou can be found the low site response amplification values of 0.61 and 0.74 for PGA and PGV, respectively, are as shown in Figures 3 and 4. As a result, the Sanchiao fault is not entirely dominated the seismic hazard in term of PGA and PGV in the vicinity of fault as shown in Figures 5 and 6. This study indicated that the site effect plays an important role in seismic hazard assessment results. (3) Not only CWB intensity, but also MMI, is used in this study to represent the level of ground shaking. The MMI intensity maps are based on a combination of estimated maximum value of the PGA and PGV, the patterns of high MMI greater than VIII in Figure 7 are similar to that of the PGV as shown in Figure 6. 


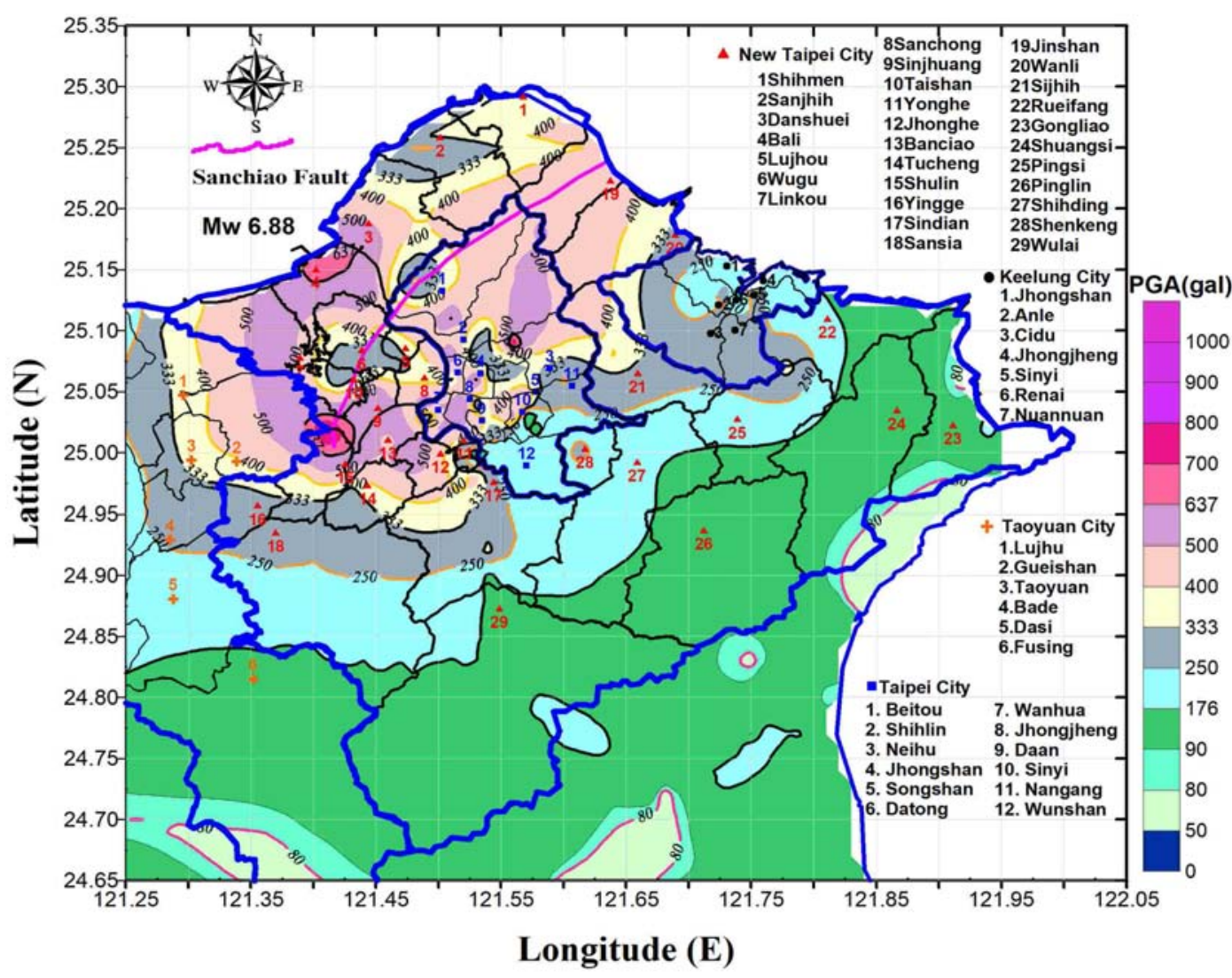

Figure 5. The PGA ShakeMap for Mw6.88 scenario earthquake on the Sanchiao active fault in northern Taiwan. Locations of the corresponding administrative districts and Sanchiao fault are also shown.

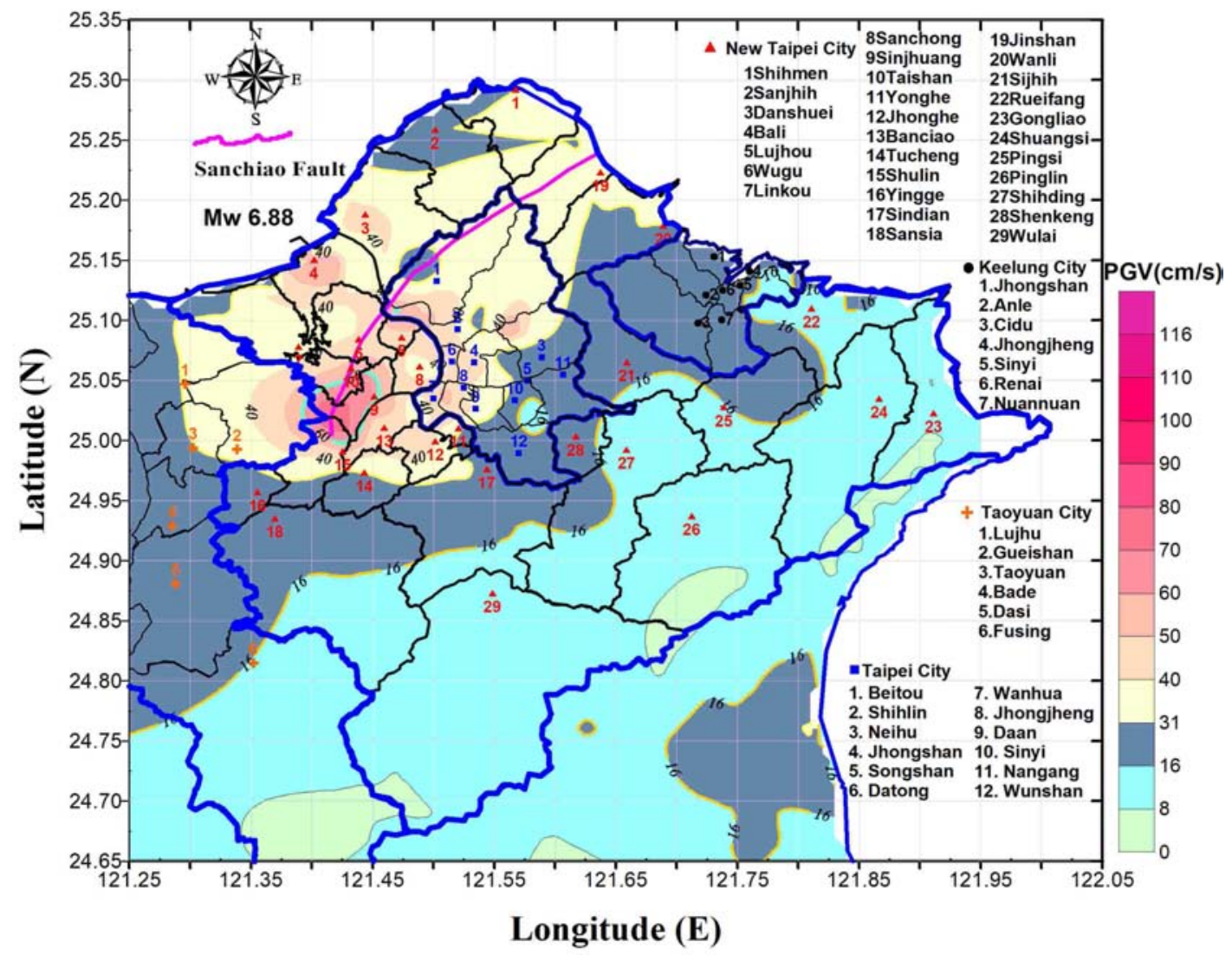

Figure 6. The PGV ShakeMap for Mw6.88 scenario earthquake on the Sanchiao active fault in northern Taiwan. Locations of the corresponding administrative districts and Sanchiao fault are also shown. 


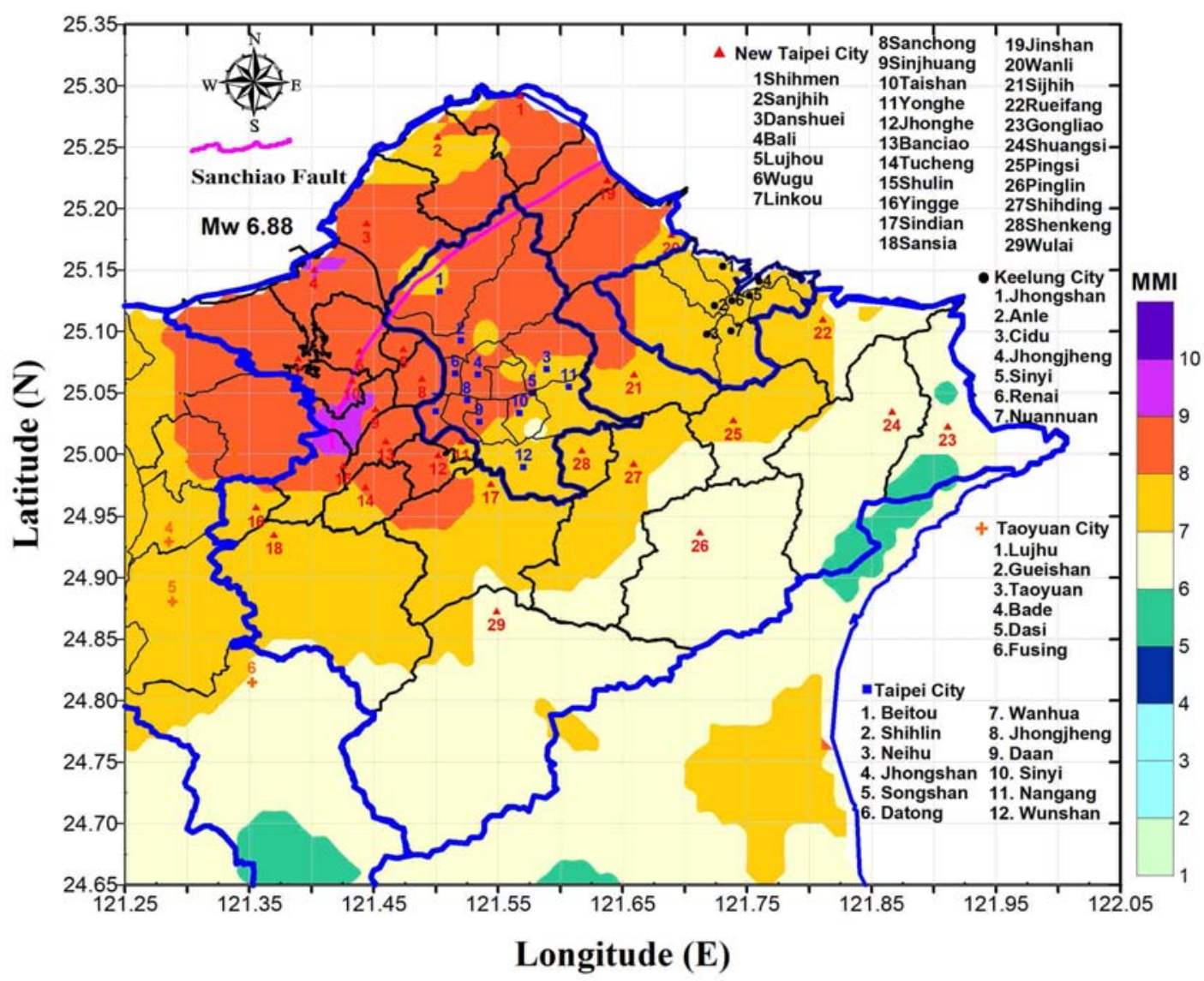

Figure 7. The MMI ShakeMap for Mw6.88 scenario earthquake on the Sanchiao active fault in northern Taiwan. Locations of the corresponding administrative districts and Sanchiao fault are also shown.

\subsection{Estimation of Potential Human Fatalities from a Scenario Earthquake}

Potential human fatality estimates were performed using the empirical function for human fatality rate age dependence for large earthquake scenarios in northern Taiwan obtained by Tsai et al., [10]. For this purpose, I used a scenario earthquake with Mw 6.88 on the Sanchiao fault. The ground motion PGA ShakeMap was calculated for an Mw 6.88 earthquake on the Sanchiao active fault by using the empirical attenuation relationships by Liu and Tsai $[6,22]$, incorporating the site response factor in the predictive model, as shown in Figure 5. Next, the age dependent fatality rate in equation 1 was combined with the impacted population data from the demographic summary [13] to calculate the number of potential fatalities, as shown in Figures 8 to 11 for Taipei City, new Taipei City, Keelung City and Taoyuan City, respectively.

The top panels in Figures 8-11 show the fatality rates for individual age groups. The middle panels in Figures 8-11 show the age distributions for a total population of $2,238,028,3,403,061,79,640$ and 689,252 in the towns with estimated seismic intensity PGA greater than 250 gals in Taipei City, new Taipei City, Keelung City and Taoyuan City, respectively as shown in Figure 5. These figures indicate that the population numbers start to decrease steadily above age 55 . Finally, the bottom panels in Figures 8-11 and Table 4 show the age distributions for 4904, 6360, 161 and 1234 fatalities in Taipei City, new Taipei City, Keelung City and Taoyuan City, respectively. For Taipei City, as shown in Figure 8 (c), the numbers of fatalities stay flat at an average of 93 for people below age 35. The fatalities then increase rapidly for those above age 45 and reach a high peak of 591 in the 60-64 age groups. The number of fatalities then drops rapidly back to 419 for those above age 85. For New Taipei City, as shown in Figure 9 (c), the numbers of fatalities stay flat at an average of 150 for people below age 35 . The fatalities then increase rapidly for those above age 45 and reach a high peak of 792 in the 60 64 age groups. The number of fatalities then drops rapidly back to 319 for those above age 85. In Keelung City, as shown in Figure 10 (c), the numbers of fatalities stay flat at an average of 3 for people below age 35 . The fatalities then increase rapidly for those above age 45 and reach a high peak of 20 in the 55-59 age groups. The number of fatalities then drops rapidly back to 11 for those above age 85 . In Taoyuan City, as shown in Figure 11 (c), the numbers of fatalities stay flat at an average of 32 for people below age 35 . The fatalities then increase rapidly for those above age 45 and reach a high peak of 139 in the 55-59 age groups. The number of fatalities then drops rapidly back to 68 for those above age 85 . 
(a)
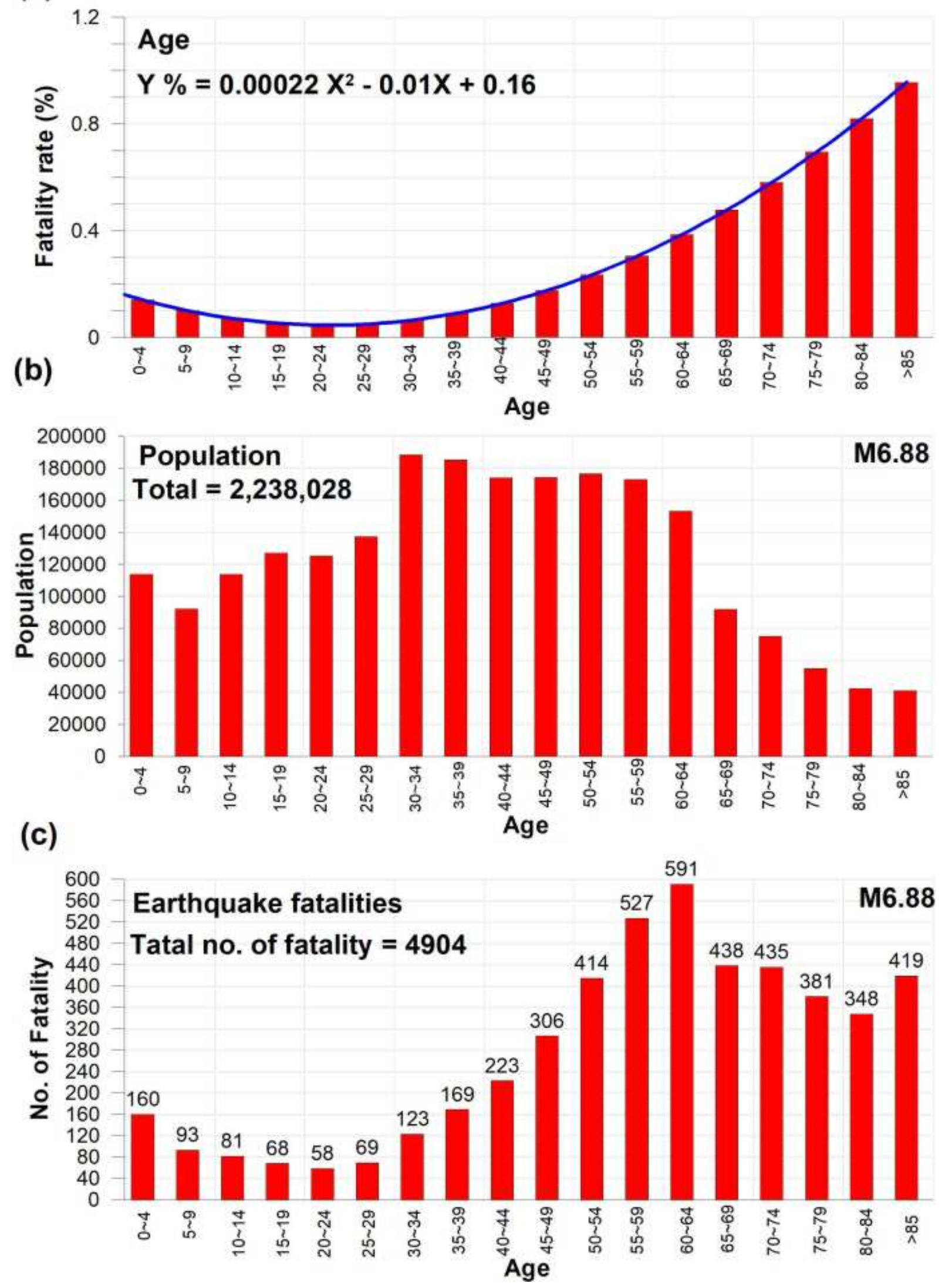

Figure 8. Earthquake fatality rates (top), population (middle), and the number of fatality (bottom) in the Taipei City estimated for an Mw 6.88 scenario earthquake on the Sanchiao active fault. A regression equation and corresponding curve on age dependence of the fatality rate is also shown in the top plot. 
(a)
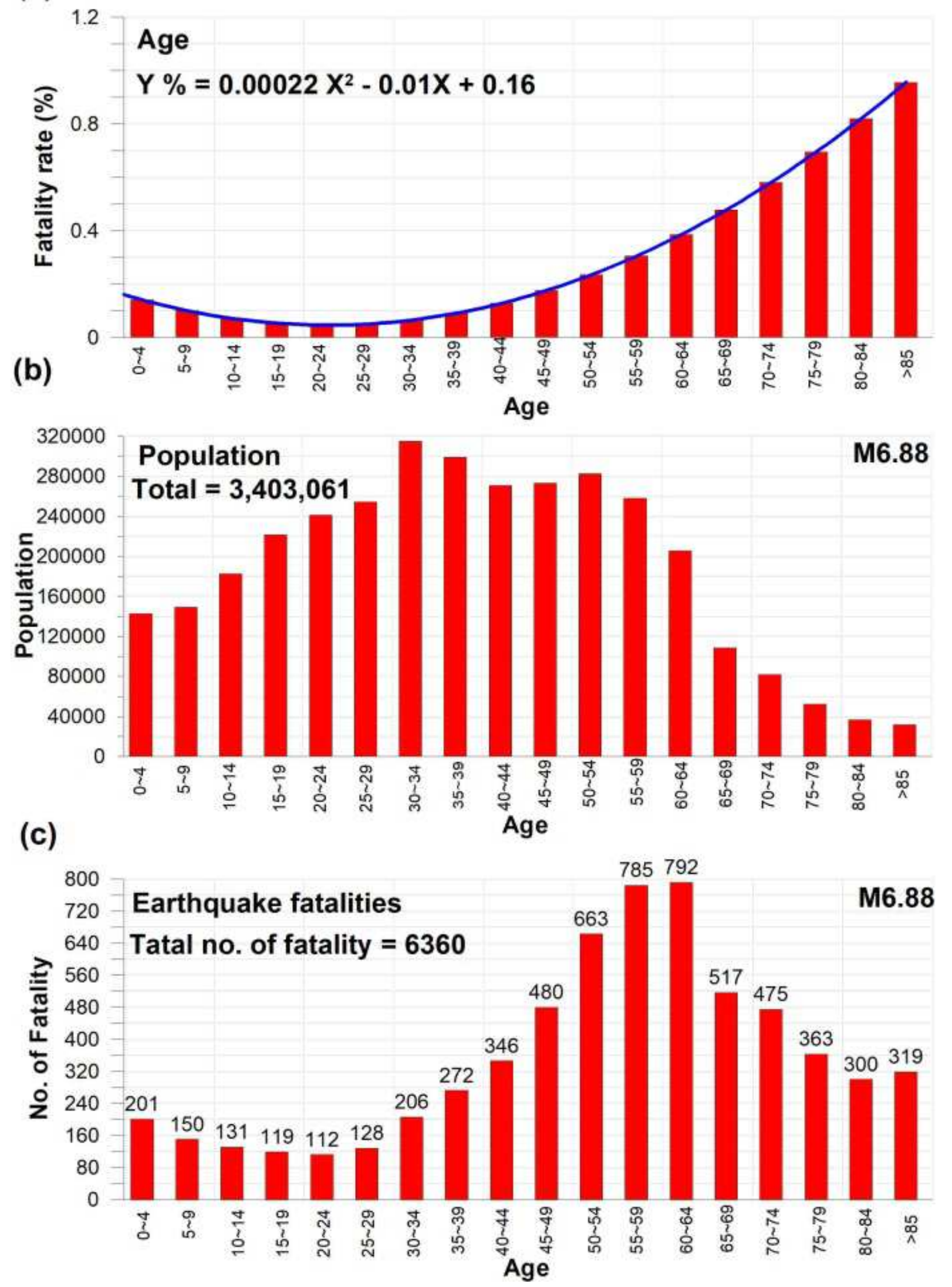

Figure 9. Earthquake fatality rates (top), population (middle), and the number of fatality (bottom) in the New Taipei City estimated for an Mw 6.88 scenario earthquake on the Sanchiao active fault. A regression equation and corresponding curve on age dependence of the fatality rate is also shown in the top plot. 
(a)
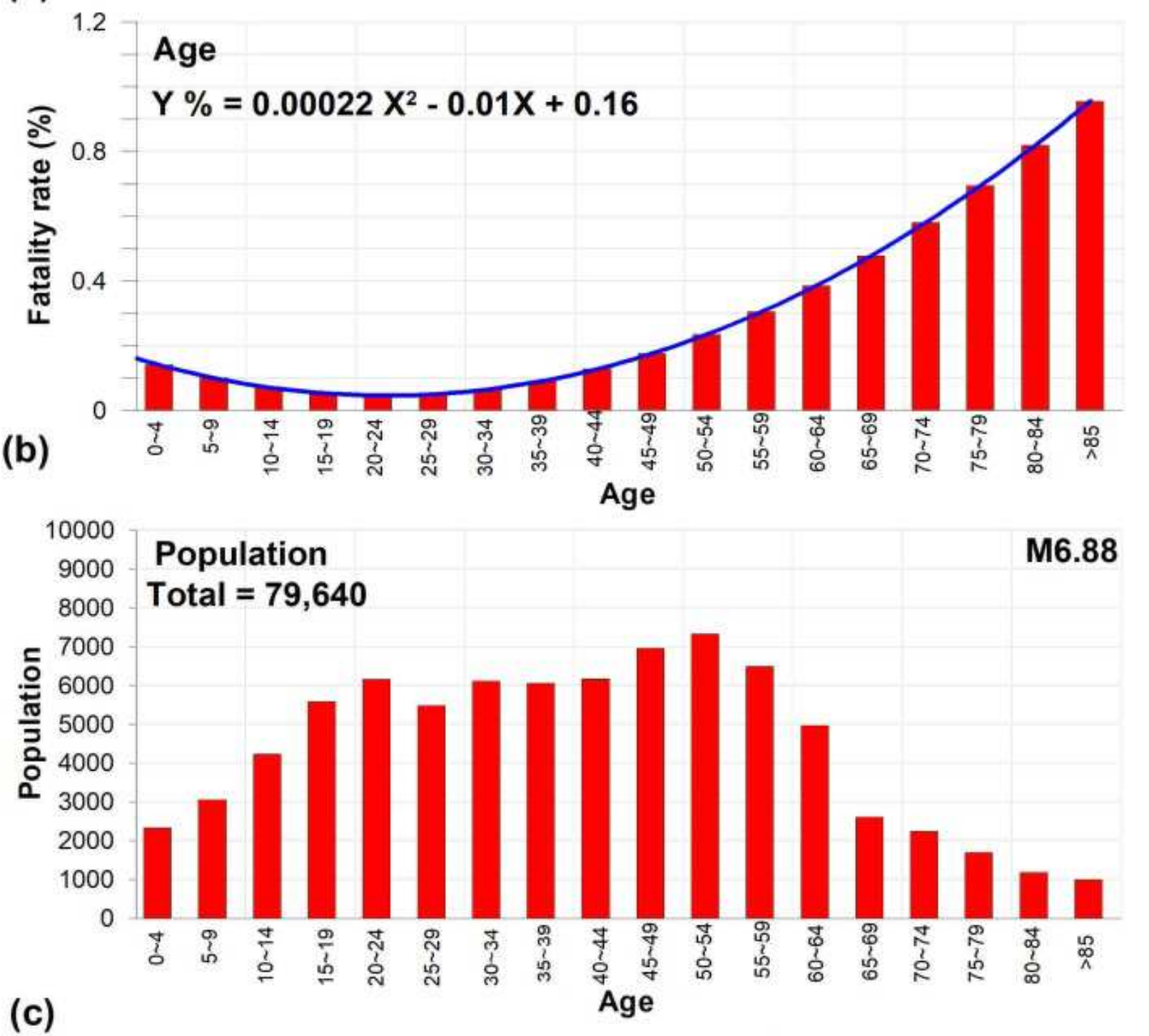

(c)

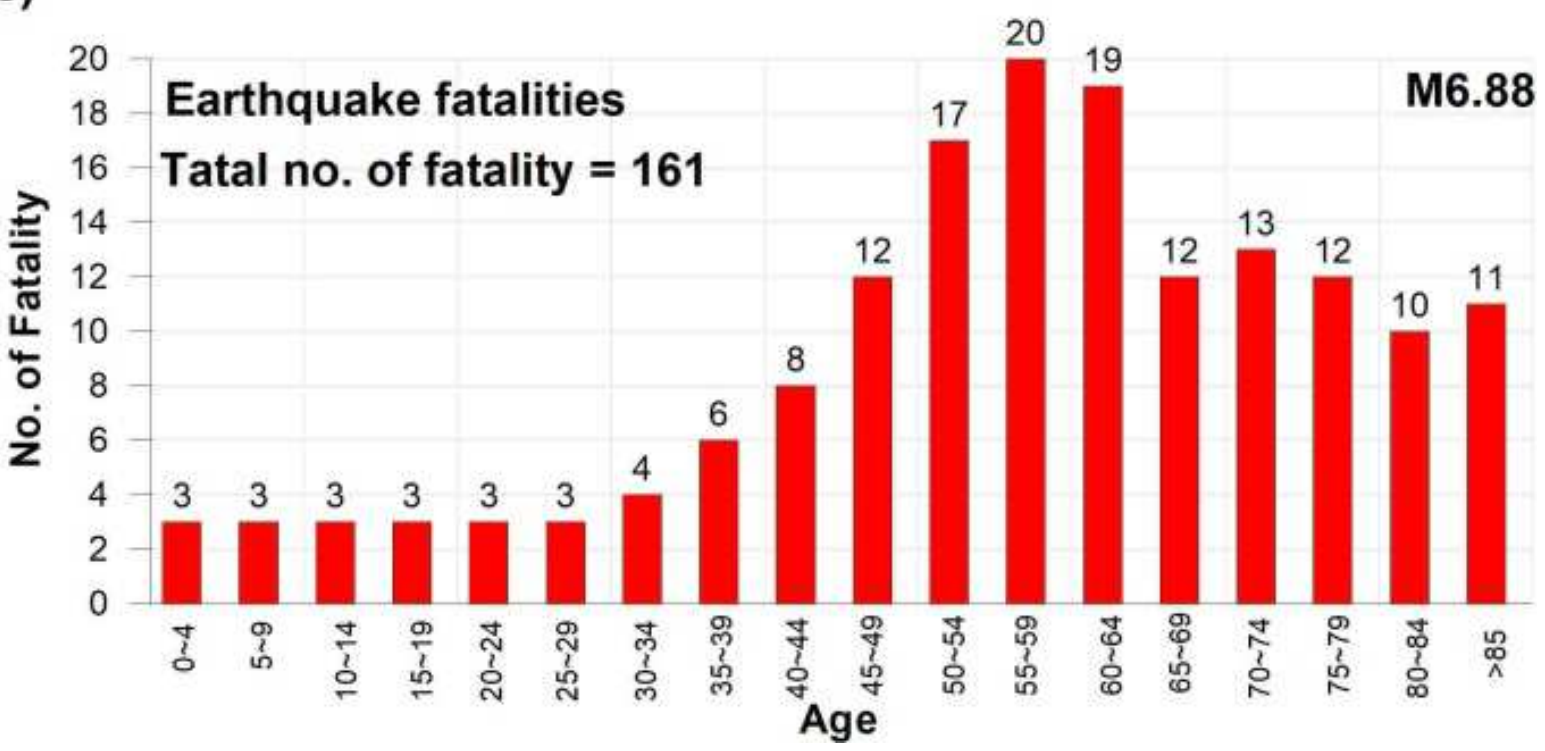

Figure 10. Earthquake fatality rates (top), population (middle), and the number of fatality (bottom) in the Keelung City estimated for an Mw 6.88 scenario earthquake on the Sanchiao active fault. A regression equation and corresponding curve on age dependence of the fatality rate is also shown in the top plot. 
(a)
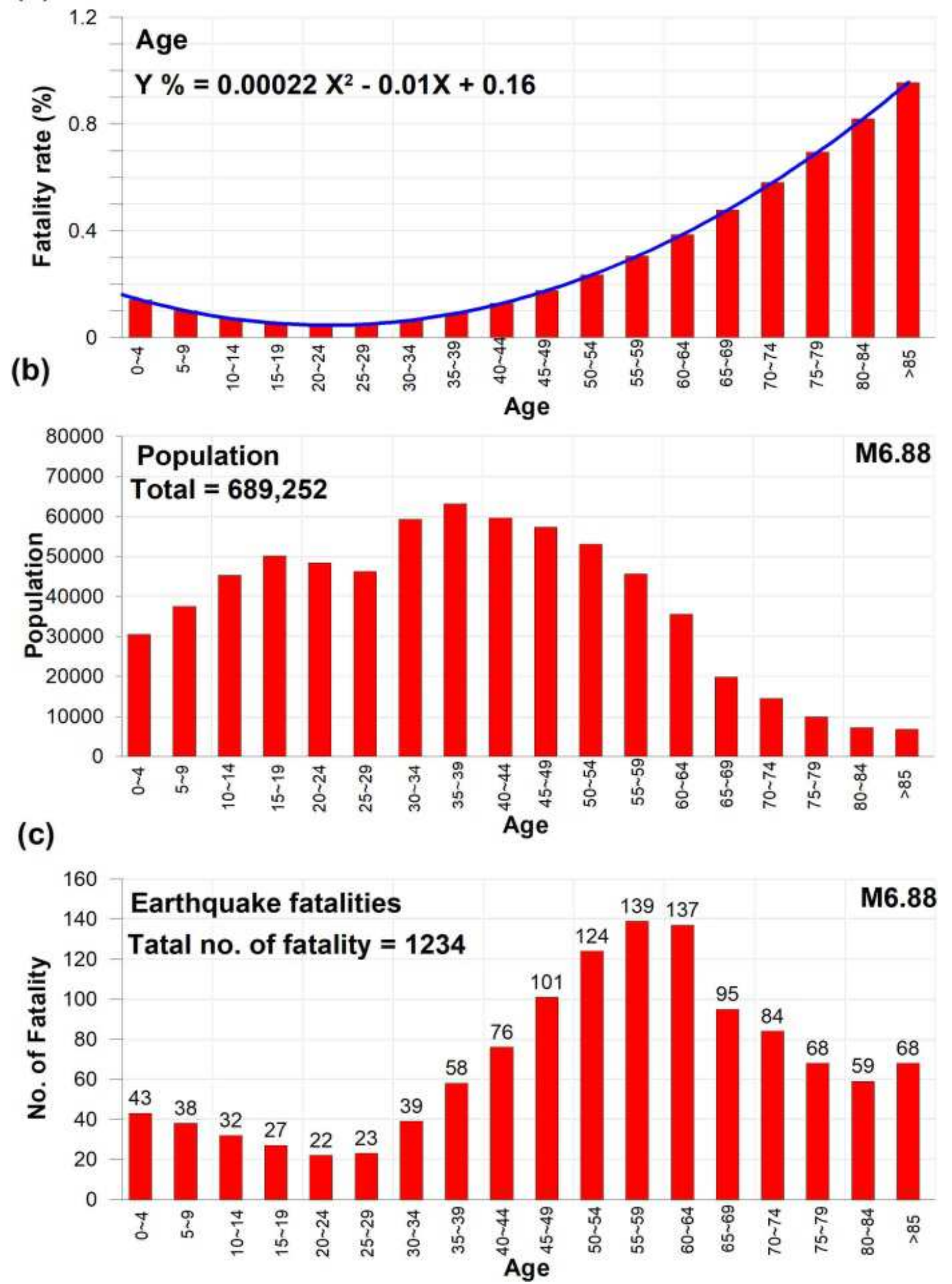

Figure 11. Earthquake fatality rates (top), population (middle), and the number of fatality (bottom) in the Taoyuan City estimated for an Mw 6.88 scenario earthquake on the Sanchiao active fault. A regression equation and corresponding curve on age dependence of the fatality rate is also shown in the top plot. 
Table 4. The number of fatality for different age groups in northern Taiwan estimated for Mw 6.88 scenario earthquake on the Sanchiao active fault.

\begin{tabular}{|c|c|c|c|c|c|c|c|c|c|c|}
\hline \multicolumn{11}{|c|}{ Taipei City } \\
\hline Age & $0 \sim 4$ & $5 \sim 9$ & $10 \sim 14$ & $15 \sim 19$ & $20 \sim 24$ & $25 \sim 29$ & $30 \sim 34$ & $35 \sim 39$ & $40 \sim 44$ & $45 \sim 49$ \\
\hline Mw6.88 & 160 & 93 & 81 & 68 & 58 & 69 & 123 & 169 & 223 & 306 \\
\hline Age & $50 \sim 54$ & $55 \sim 59$ & $60 \sim 64$ & $65 \sim 69$ & $70 \sim 74$ & $75 \sim 79$ & $80 \sim 84$ & $>85$ & & Total \\
\hline Mw6.88 & 414 & 527 & 591 & 438 & 435 & 381 & 348 & 419 & & 4904 \\
\hline \multicolumn{11}{|c|}{ New Taipei City } \\
\hline Age & $0 \sim 4$ & $5 \sim 9$ & $10 \sim 14$ & $15 \sim 19$ & $20 \sim 24$ & $25 \sim 29$ & $30 \sim 34$ & $35 \sim 39$ & $40 \sim 44$ & $45 \sim 49$ \\
\hline Mw6.88 & 201 & 150 & 131 & 119 & 112 & 128 & 206 & 272 & 346 & 480 \\
\hline Mw6.88 & 663 & 785 & 792 & 517 & 475 & 363 & 300 & 319 & & 6360 \\
\hline \multicolumn{11}{|c|}{ Keelung City } \\
\hline Age & $0 \sim 4$ & $5 \sim 9$ & $10 \sim 14$ & $15 \sim 19$ & $20 \sim 24$ & $25 \sim 29$ & $30 \sim 34$ & $35 \sim 39$ & $40 \sim 44$ & $45 \sim 49$ \\
\hline Mw6.88 & 3 & 3 & 3 & 3 & 3 & 3 & 4 & 6 & 8 & 12 \\
\hline Age & $50 \sim 54$ & $55 \sim 59$ & $60 \sim 64$ & $65 \sim 69$ & $70 \sim 74$ & $75 \sim 79$ & $80 \sim 84$ & $>85$ & & Total \\
\hline Mw6.88 & 17 & 20 & 19 & 12 & 13 & 12 & 10 & 11 & & 161 \\
\hline \multicolumn{11}{|c|}{ Taoyuan City } \\
\hline Age & $0 \sim 4$ & $5 \sim 9$ & $10 \sim 14$ & $15 \sim 19$ & $20 \sim 24$ & $25 \sim 29$ & $30 \sim 34$ & $35 \sim 39$ & $40 \sim 44$ & $45 \sim 49$ \\
\hline Age & $50 \sim 54$ & $55 \sim 59$ & $60 \sim 64$ & $65 \sim 69$ & $70 \sim 74$ & $75 \sim 79$ & $80 \sim 84$ & $>85$ & & Total \\
\hline Mw6.88 & 124 & 139 & 137 & 95 & 84 & 68 & 59 & 68 & & 1234 \\
\hline
\end{tabular}

In summary, the earthquake scenarios using Mw 6.88 on the Sanchiao fault to estimate potential human casualties. As a result, from Figure 2 and Figures 8-11 mentioned above, I can find the following features: (1) the fatalities are 4904, 6360, 161 and 1234 in Taipei City, New Taipei City, Keelung City and Taoyuan City, respectively for the Mw 6.88 scenarios earthquake. Although the all number of fatalities are more in New Taipei City than Taipei City. The number of fatalities above age 85 is 419 and 319 in Taipei City and New Taipei City, respectively. It is just the opposite that the number and percentage of fatalities above age 85 are more in Taipei City with values 419 and $8.54 \%$ than New than Taipei City with values of 319 and $5.02 \%$. The Taipei City Government should pay more attention in emergency plans for earthquake for those elder people ages above 85. (2) The total number fatalities are 12,659 for the Mw 6.88 scenarios earthquake in northern Taiwan. The structural failure and the building types were the primary cause of death for the victims of the Chi-Chi earthquake. Pai et al. [26] indicated the main cause lies in the difference was the capacity of the different building types to resist strong shaking. When a great earthquake strikes, these old houses are vulnerable to collapse. In spite of building code revisions after 1999, better building quality is expected and corresponding fatality rate should be reduced. Unfortunately, in northern Taiwan, these households whose residences are over 40 years old, including bungalows and 2-3 stories houses. Many of them are still in use in these metropolitan area where population density is above 20,000 per $\mathrm{km}^{2}$. Many person concern and worry about the capacity of old buildings to resist strong shaking. In case of a big earthquake, the consequences would be inconceivable. (3) It is not expected that the number and percentage of fatalities are 1234 and $9.75 \%$, respectively in Taoyuan City. However, considering the residents of 885,217 live in Lujhu, Gueishan, Taoyuan and Bade of Taoyuan City. The distances from the above-mentioned regions to Sanchiao fault are no more than $20 \mathrm{~km}$. The higher number of fatalities in Taoyuan City is considered reasonable.

Finally, the results of my study can provide a valuable database for site evaluation of critical facilities in relatively high potential earthquake hazard regions. They also will be useful for land planning. Furthermore, the results will enable both local and central governments in Taiwan to take notice of potential earthquake threat in these areas, as well as to improve decision making with respect to emergency preparedness, response, and recovery activities for earthquakes.

\section{Conclusions}

According to above results and discussion, my findings are summarized as follows:

(1) From the PGA contour map for an Mw6.88 scenario earthquake on the Sanchiao active fault in northern Taiwan, the results reveal that high PGA areas greater than 400 gals are located in the regions inside the yellow lines as shown in Figure 5. Furthermore, the areas of PGA above 500 gals are as shown in the regions filled with purple in Figure 5. The areas of high PGA greater than 637 gal are located in the northern Bali and the border area of Sinjhuang and Shulin. Similarly, the areal patterns of high PGV greater than $31 \mathrm{~cm} / \mathrm{s}$ are similar to that of the PGA. In addition, the high PGV area greater than $60 \mathrm{~cm} / \mathrm{s}$ are located in the border area of Sinjhuang, Taishan and Shulin. The pattern of high MMI greater than VIII, is similar to the contour pattern of the PGV greater than $31 \mathrm{~cm} / \mathrm{s}$. In summary, the ShapeMaps shown in Figures 5-7 can provide critical information to assess potential earthquake hazards in northern Taiwan.

(2)The above-mentioned areas with high PGA and PGV, especially in the border area of Sinjhuang and Shulin are due to the combined effects of the large site response factors and Sanchiao fault. Furthermore, not always the highest PGA values distributed in the fault rupture areas due to the site effect of low response factors, especially, in northwestern Beitou with low site response amplification values of 0.61 and 0.74 for PGA and PGV, respectively. 
This study indicated that the site effects play an important role in seismic hazard assessment results.

(3) In addition, the potential human fatalities were estimated by assuming a scenario Mw 6.88 earthquake on the Sanchiao active fault in northern Taiwan. As a result, the numbers of fatalities tend to increase rapidly for people above age 45 for four cities. The fatalities reached a high peak in age groups of 60-64 for Taipei City and New Taipei City as well as in age groups of 5559 for Keelung City and Taoyuan City. Moreover, the fatalities are 4904, 6360, 161 and 1234 in Taipei City, New Taipei City, Keelung City and Taoyuan City, respectively for the scenarios earthquake. The Taipei City Government should pay more attention that the number and percentage of fatalities above age 85 are more in Taipei City with values of 419 and $8.54 \%$ than New than Taipei City with values of 319 and $5.02 \%$.

(4) It is surprising that the number and percentage of fatalities are 1234 and $9.75 \%$, respectively in Taoyuan City. However, considering the residents of 885,217 live in Lujhu, Gueishan, Taoyuan and Bade of Taoyuan City. The distances from the above-mentioned regions to Sanchiao fault are no more than $20 \mathrm{~km}$. The higher number of fatalities in Taoyuan City is considered reasonable. Finally, the results of this paper will enable both local and central governments in Taiwan to take notice of potential earthquake threat in these areas, as well as to improve decision making with respect to emergency preparedness, response, and recovery activities for earthquakes in northern Taiwan.

\section{Acknowledgements}

I thank the Central Geological Survey of Taiwan for providing the fault data. I also appreciate greatly anonymous reviewers for their valuable comments, which improved the article. This research was supported by the Ministry of Science and Technology (MOST) of the Republic of China with grant number MOST107-2116-M-244-001 and MOST108-2116-M-244-001.

\section{References}

[1] CGS (Central Geological Survey), 2014: Active fault of Taiwan, Retrieved Mar. 15, 2014 from http://fault.moeacgs.gov.tw/MgFault/Home/pageMap?LFun=3

[2] Yeh, C. H., C. H. Loh, and K. C. Tsai, 2006: Overview of Taiwan earthquake loss estimation system, Nat. Hazards 37 23-37, doi: 10.1007/s11069-005-4654-z.

[3] Liu, K. S., Y. B. Tsai, and B. S. Lin, 2013a: A Study on Fault Type and Site Effect (Vs30) Parameters in the Attenuation Relationships of Peak Ground Acceleration and Velocity in Ilan, Taiwan, Bull. Seismol. Soc. Am. 103, 1823-1845, doi: $10.1785 / 0120120065$.

[4] Liu, K. S. Y. B. Tsai, and K. P. Chen, 2013b: Estimation of Seismic Hazard Potential in Taiwan Based on ShakeMaps, Nat
Hazards Vol. 69, No3, 2233-2262, doi: 10.1007/s11069-013-0804-x.

[5] Liu, K. S. Y. B. Tsai, C. H. Chang and B. S. Lin, 2014: A Study of Site Effects in Ilan, Taiwan Based on Attenuation Relationships of Spectral Acceleration, Bull. Seismol. Soc. Am. 104, 2467-2490, doi: 10.1785/0120130238.

[6] Liu, K. S., and Y. B. Tsai, 2015a: A refined Vs30 map for Taiwan based on attenuation relationships of ground motion. Terr. Atmos. Ocean. Sci., Vol. 26, No. 6, 631-653, doi: 10.3319/TAO.2015.05.11.01 (TC).

[7] Liu, K. S., 2017, Estimation of Seismic Ground Motions and Attendant Potential Human Fatalities from Scenario Earthquakes on the Chishan Fault in Southern Taiwan. Terr. Atmos. Ocean. Sci., Vol. 28, No. 5, 715-737.

[8] Wald, D. J., V. Quitoriano, T. Heaton, and H. Kanamori, 1999: Relationships between peak ground acceleration, peak ground velocity and Modified Mercalli Intensity in California, Earthquake Spectra 15 557-564, doi: 10.1193/1.1586058.

[9] Liu, K. S. and Y. B. Tsai, 2016a: Microzonation of Seismic Hazards and Assessment of Potential Human Fatality in Chianan Area, Taiwan. Bull. Seismol. Soc. Am. Vol. 106, No1, 141-157, doi: 10.1785/0120150182.

[10] Tsai, Y. B., T. M. Yu, H. L. Chao, and C. P. Lee, 2001: Spatial Distribution and Age Dependence of Human-Fatality Rates from the Chi-Chi, Taiwan, Earthquake of 21 September 1999, Bull. Seismol. Soc. Am. 91 1298-1309, doi: $10.1785 / 0120000740$.

[11] Taipei City Government, 2016: Taipei City Disaster Prevention and Relief Plan. Taipei: Taipei City Government. Retrieved Dec. 18, 2016 fromhttp://www.eoc.gov.taipei/taipeicityems1_public/Org/Dis asterPrevention.

[12] New Taipei City Government, 2017: New Taipei City Disaster Prevention and Relief Plan. New Taipei City: New Taipei City Government. Retrieved Dec. 20, 2017 from http://www.dsc.ntpc.gov.tw/BoardB.asp?Kind=101050100.

[13] National Statistics, Republic of China (Taiwan), 2014: Age structure of the resident population by township/city/district. Retrieved Apr. 21, 2014 from http://eng.stat.gov.tw/mp.asp? $\mathrm{mp}=5$.

[14] Shyu, J. B. H., K. Sieh, Y.-G. Chen, and C.-S. Liu, 2005: Neotectonic architecture of Taiwan and its implications for future large earthquakes, J. Geophys. Res., 110, B08402, doi: 10.1029/2004JB003251.

[15] Shieh, Y.-T., 2000: The paleogeography of the ancient Taipei lakebed in the K'anghsi Period (in Chinese with English abstract), J. Geogr. Sci., 27, 85-95.

[16] Liu, K. S. and Y. B. Tsai, 2014: Microzonation of Seismic Hazard Potential in Tainan Area, Journal of Architure. 89, 153-176, doi: 10.3966/101632122014090089009.

[17] Liu, K. S., and Y. B. Tsai, 2015b: Microzonation of seismic hazard potential in Chiayi area. Journal of the Chinese Institute of Civil and Hydraulic Engineering. V27, No4, 263-275. doi: 10.6653/JoCICHE.

[18] Liu, K. S. and Y. B. Tsai, 2016b: Microzonation of Seismic Hazard Potential in Kaohsiung Area, Journal of Architure. 96, 153-176. 
[19] Liu, K. S., 2019: Estimation of Seismic Ground Motions and Attendant Potential Human Fatalities from Scenario Earthquakes on the Sanchiao Fault in Taipei City, Taiwan. Earth Sciences, 8, No. 2, 81-93.

[20] Wells D. L. and K. J. Coppersmith, 1994: New Empirical Relationships among Magnitude, Rupture Length, Rupture Width, Rupture Area, and Surface Displacement, Bull. Seismol. Soc. Am. 84, 974-1002.

[21] Shin, T. C., and T. L. Teng (2001). An overview of the 1999 Chi-Chi, Taiwan, earthquake, Bull. Seismol. Soc. Am. 91, 895913.

[22] Liu, K. S. and Y. B. Tsai, 2005: Attenuation relationships of peak ground acceleration and velocity for crustal earthquakes in Taiwan, Bull. Seismol. Soc. Am. 95, 1045-1058, doi: $10.1785 / 0120040162$.
[23] Liu, K. S., T. C. Shin and Y. B. Tsai, 1999: A free field strong motion network in Taiwan: TSMIP, TAO, Vol 10, No 2, 377-396.

[24] Coburn, A., and R. Spence, 1992: Earthquake Protection, John Wiley \& Sons, Chichester, U.K., 355 pp.

[25] Yu, T. M., 2004: The Relations of Earthquake Disasters with Respect to Surface Fault Rupture, Crustal Movement, and Strong Ground Motion: Using Two Central Taiwan Earthquakes in 1935 and 1999 as Examples. Ph. D. Thesis, National Central University, Chungli, Taiwan, 209 pp. (in Chinese with English abstract).

[26] Pai, C. H. Y. M. Tien, and T. L. Teng, 2007: A study of the human-fatality rate in near-fault regions using the Victim Attribute Database, Nat Hazards Vol. 42, No 1, 19-35. 